\title{
Vestibular neurophysiology: a collection of papers in honor of the career of Jay Goldberg
}

\author{
K. E. Cullen · B. J. Yates
}

Published online: 30 March 2011

(C) Springer-Verlag 2011

Approximately 80 neuroscientists who study the vestibular and auditory systems gathered in Reykholt, Borgarfjörður, Iceland, on 16-17 August 2010, to pay tribute to Jay M. Goldberg. The Reykholt meeting was a satellite of the XXVI Bárány Society Meeting. A photograph and listing of the meeting participants are provided in Fig. 1.

Goldberg started his scientific career in the 1960s studying the processing of auditory signals by the central nervous system. By the 1970s, his interest shifted to the coding of head movements by the vestibular system. In a seminal series of manuscripts, Goldberg and his longtime colleague César Fernández described for the first time the dynamics governing the responses of afferents innervating semicircular canals (Fernández and Goldberg 1971, Goldberg and Fernández 1971a, b) and otolith organs (Fernández and Goldberg 1976a, b, c) to linear and angular accelerations. This work was followed by a second series of heroic experiments establishing that afferent discharge regularity is correlated with innervation patterns as well as the locations of terminals in the neuroepithelium (Fernández et al. 1988, 1990; Baird et al. 1988; Goldberg et al. 1990a, b).

K. E. Cullen

McGill University, Montreal, QC, Canada

B. J. Yates $(\bowtie)$

University of Pittsburgh, Pittsburgh, PA, USA

e-mail: byates@pitt.edu
Taken together, this remarkable body of work has set the stage for current and future studies in the field of vestibular neurophysiology.

Goldberg's more recent experiments have continued to provide important new insights into how vestibular signals are transduced in the periphery and transformed as they are processed by the central nervous system. His current work focusing on the synaptic and cellular physiology of receptors and afferents has furthered our understanding of the mechanisms underlying the morphological and physiological diversity of the peripheral vestibular system, thereby providing a crucial foundation on which the next generation of vestibular research will be built. Additionally, in the process of conducting his research, Goldberg has had a profound impact on his students, collaborators, and colleagues. He has not only trained a large fraction of the vestibular neuroscientists who continue to move the field forward, but the influence of his work and his standard of scientific excellence continues to inspire young researchers in the field.

This special issue contains 25 articles submitted by Goldberg's collaborators, colleagues, trainees, and friends, all of whom have been profoundly influenced by his research findings, integrity, and dedication to science. Amongst the articles are 10 reviews and 15 original research studies that discuss how sensory inputs impinging on the inner ear are detected and reflected in the firing of eighth cranial nerve afferents; how the signals are modified as they are processed within the central nervous system; and how they impact a number of behavioral and physiological responses, including the control of balance, eye movements, and blood pressure. These articles are testimony to the accomplishments in the field of vestibular neurophysiology spurred by Goldberg's work during the past 40 years. 


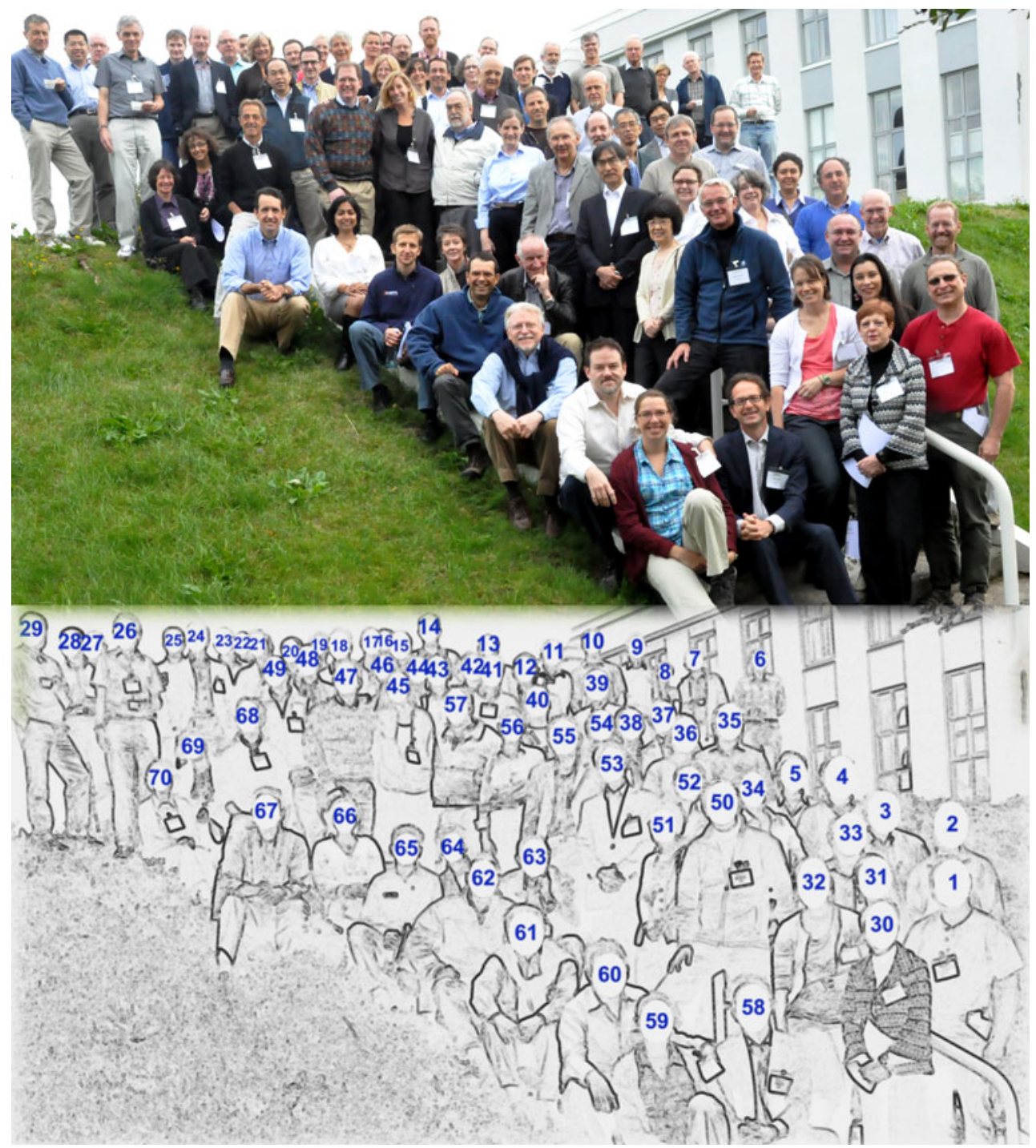

Fig. 1 Photograph of the participants in the August 16-17, 2010 meeting in honor of Jay Goldberg. Key 1, Daniel Merfeld, 2, Benton Lawson, 3, Neil Shephard, 4, Nicolas Perez, 5, Elham Khojasteh, 6, Angus Rupert, 7, Sigurður Stefánsson, 8, Ingibjörg Hinriksdottir, 9, Laurence Young, 10, Alan Brichta, 11, Ian Curthoys, 12, John Carey, 13, Bill Yates, 14, Einar Hjaltested, 15, Sergei Yakushin, 16, Einar J Einarsson, 17, Bergthora Baldursdottir, 18, Pierre-Paul Vidal, 19, Anna Hafström, 20, Maurice Chacron, 21, Eva-Maj Malmström, 22, Omar Main, 23, Brian Day, 24, Steve Lisberger, 25, Richard Penninger, 26, Arthur Mallinson, 27, Richard Fitzpatrick, 28, Wuqing Wang, 29, Neil Longridge, 30, Margaret Sharpe, 31, Rebecca Lim, 32, Paivi Jordan, 33, Paul Smith, 34, Shawn Newlands, 35, Cynthia Darlington, 36, James Phillips, 37, Chang-Hee Kim, 38, Hiroyuki Ito, 39, Bernhard Hess, 40, Oz Zur, 41, Eric Young, 42, Shelley Cross, 43,

\section{References}

Baird RA, Desmadryl G, Fernández C, Goldberg JM (1988) The vestibular nerve of the chinchilla. II. Relation between afferent response properties and peripheral innervation patterns in the semicircular canals. J Neurophysiol 60:182-203

Fernández C, Goldberg JM (1971) Physiology of peripheral neurons innervating semicircular canals of the squirrel monkey. II.
Hans Straka, 44, Itsaso Olasagasti, 45, Kathleen Cullen, 46, Ruth Anne Eatock, 47, Lloyd Minor, 48, Robby Vanspauwen, 49, Chunfu Dai, 50, Mans Magnusson, 51, Junko Fukushima, 52, Julia Dlugaiczyk, 53, Kikuro Fukushima, 54, Robert Schor, 55, Graham Barnes, 56, Anna Lysakowski, 57, Jay Goldberg, 58, Floris Wuyts, 59, Jocelyn Songer, 60, Chris Holt, 61, Bill Brownell, 62, Meir Plotnik, 63, Stuart Mossman, 64, Beth Lange, 65, Francois Asseman, 66, Shilpa Chatlani, 67, Charley Della Santina, 68, Giuseppe Agus, 69, Dora Angelaki, 70, Dianne Broussard. Participants not shown Francesco Boselli, Sascha Du Lac, Lisa Goulart, David Hampson, Timothy Hullar, Rolf Johansson, Michael Katekar, Eva Noring, Richard Rabbitt, Mario Ruggero, Jessica Vitkovic. Photo by Floris Wuyts

Response to sinusoidal stimulation and dynamics of peripheral vestibular system. J Neurophysiol 34:661-675

Fernández C, Goldberg JM (1976a) Physiology of peripheral neurons innervating otolith organs of the squirrel monkey. I. Response to static tilts and to long-duration centrifugal force. J Neurophysiol 39:970-984

Fernández C, Goldberg JM (1976b) Physiology of peripheral neurons innervating otolith organs of the squirrel monkey. II. Directional 
selectivity and force-response relations. J Neurophysiol 39:985-995

Fernández C, Goldberg JM (1976c) Physiology of peripheral neurons innervating otolith organs of the squirrel monkey. III. Response dynamics. J Neurophysiol 39:996-1008

Fernández C, Baird RA, Goldberg JM (1988) The vestibular nerve of the chinchilla. I. Peripheral innervation patterns in the horizontal and superior semicircular canals. J Neurophysiol 60:167-181

Fernández C, Goldberg JM, Baird RA (1990) The vestibular nerve of the chinchilla. III. Peripheral innervation patterns in the utricular macula. J Neurophysiol 63:767-780

Goldberg JM, Fernández C (1971a) Physiology of peripheral neurons innervating semicircular canals of the squirrel monkey. 3 .
Variations among units in their discharge properties. J Neurophysiol 34:676-684

Goldberg JM, Fernández C (1971b) Physiology of peripheral neurons innervating semicircular canals of the squirrel monkey. I. Resting discharge and response to constant angular accelerations. J Neurophysiol 34:635-660

Goldberg JM, Desmadryl G, Baird RA, Fernández C (1990a) The vestibular nerve of the chinchilla. IV. Discharge properties of utricular afferents. J Neurophysiol 63:781-790

Goldberg JM, Desmadryl G, Baird RA, Fernández C (1990b) The vestibular nerve of the chinchilla. V. Relation between afferent discharge properties and peripheral innervation patterns in the utricular macula. J Neurophysiol 63:791-804 